Article

\title{
Empirical Analysis Revealing Privileged Chemical Space of Cosmetic Preservatives
}

\author{
Michael P. Storz * and Lea Holsten
}

Citation: Storz, M.P.; Holsten, L. Empirical Analysis Revealing Privileged Chemical Space of Cosmetic Preservatives. Cosmetics 2021, 8, 80. https://doi.org/ $10.3390 /$ cosmetics 8030080

Academic Editor: Edith Filaire

Received: 5 August 2021

Accepted: 26 August 2021

Published: 31 August 2021

Publisher's Note: MDPI stays neutral with regard to jurisdictional claims in published maps and institutional affiliations.

Copyright: (c) 2021 by the authors. Licensee MDPI, Basel, Switzerland. This article is an open access article distributed under the terms and conditions of the Creative Commons Attribution (CC BY) license (https:// creativecommons.org/licenses/by/ $4.0 /)$.
Ashland Specialties Deutschland GmbH, 22851 Norderstedt, Germany; lea.holsten@ashland.com

* Correspondence: michael.storz@ashland.com

\begin{abstract}
Most cosmetic products require preservation to prevent microbial contamination and to ensure consumer safety. Due to regulatory restrictions and rejection by consumers, preservative options have become limited and the development of novel solutions is needed. This search can be guided by knowledge about favorable chemical space for cosmetic preservatives. Therefore, we used preservatives allowed in the EU as training set and calculated various molecular properties. Empirical analysis revealed two separated areas of privileged chemical space with the net charge as distinctive property. The first area comprises the group of neutral and anionic preservatives and is characterized by low molecular size as well as limited hydrogen-bonding capacity, polarity, and flexibility. The second area includes cationic preservatives, which are rather diffusely distributed regarding molecular weight and hydrogen-bonding, however, all members share high flexibility. Both groups significantly differ from antibiotics, reflecting the specific requirement of cosmetic preservation. The molecular properties defining the privileged chemical space are easy to calculate, and thus, can provide guidance for the development of novel preservatives.
\end{abstract}

Keywords: cosmetic preservation; antimicrobial activity; empirical analysis; molecular properties; physicochemical properties; chemical space

\section{Introduction}

Microbial contamination of cosmetic products is limiting shelf life and can pose a significant health risk for consumers [1]. To prevent spoilage by contamination with microorganisms, preservatives are typically added to ensure that the cosmetic composition remains free of microbial contamination for an adequately long period. Thereby, antimicrobial activity should be effective over a broad-spectrum of microorganisms and should persist longer than expected shelf-life plus the usage time. However, according to the Rapid Alert System (RAPEX) of the European Commission (EC), 61 cosmetic products were recalled during 2016 and 2020, as they present a serious risk due to microbiological contamination [2].

In the EU, Annex V of the Regulation (EC) No. 1223/2009 on cosmetic products provides a list of substances, which can be added to cosmetic products with the intention to preserve the composition from microbial contamination [3]. However, use concentrations are restricted, in many cases resulting in insufficient antimicrobial protection. Many ingredients negatively impact odor or color of the cosmetic formulation, and disturbance of the emulsifying system can lead to significant change of viscosity or even 'breaking' of emulsions. Furthermore, some preservatives are, despite of their documented safety, not well accepted by consumers. Formaldehyde releasers are a major class of Annex V preservatives, however, reports about carcinogenicity at high levels [4] and skin sensitizing potential [5], which were regulatory considered by maximum use concentrations, led to the disappearance in cosmetic products. Both the antimicrobial effect, as well as toxicological effects on humans, are based on alkylation reactions reflecting the high electrophilicity of formaldehyde [6,7]. Similarly, isothiazolinones, sulfur dioxide released by sulfites, 
organomercuric agents, bronidox, bronopol, and silver react with biopolymers, in particular with thiol groups of proteins [8-13].

Combining limited applicability of many preservatives and rejection by consumers, there is a depletion of usable preservatives, and thus, modern options that are not based on chemical reactivity are needed to ensure adequate preservation of cosmetics. The search for novel antimicrobials can be guided by analysis of preservatives with accepted mechanisms-of-action.

Molecular properties of substances are determinant factors for interaction with their immediate surrounding. This becomes impressively clear by the pioneering work of Lipinski and coworkers, who analyzed the influence of various chemical and physical properties on oral bioavailability of drugs in humans [14]. Thereby, they formulated the "rule of five" for molecular properties of drugs, stating that poor absorption or permeation after oral intake in humans is more likely when (1) there are more than 5 H-bond donors; (2) the molecular weight is over $500 \mathrm{~g} / \mathrm{mol}$; (3) the $\log \mathrm{P}$ is over 5 ; (4) there are more than $10 \mathrm{H}$ bond acceptors (expressed as the sum of nitrogen and oxygen atoms). Various adaptations and extensions were proposed in the field of drug discovery. Veber et al. noticed the importance of the number of rotatable bonds (nrotb) and topical polar surface area (tPSA) as determining factors for good oral bioavailability in rats [15].

Regarding preservation of cosmetic formulations, it seems intuitive to us that molecular properties of substances have direct influence on antimicrobial activity on two levels:

(1) Availability of antimicrobial substance at their target site: most cosmetic formulations are complex systems composed of multiple phases. For example, many creams and lotions are $\mathrm{o} / \mathrm{w}$ emulsions containing a liquid oily phase dispersed in a continuous aqueous phase stabilized by emulsifiers. Shampoos and body washes are also inhomogeneous systems as they contain surfactants, which can form aggregates in water, such as micelles. To be effective against microbes, preservatives need to get in close contact to microbial cells to allow adequate interaction, i.e., they must be present in sufficient concentration in the bulk water. Various studies revealed lower antimicrobial activity in cosmetic formulations compared to aqueous solution [16]. For example, Tschierske et al. has shown that individual interactions between an antimicrobial agent and specific emulsifiers determine the degree of binding, which reduces the availability for target interaction and leads to a loss in activity [17].

(2) Preservative/microbe interaction: the interaction between the antimicrobial substance and the microbe is expected to strongly depend on molecular properties. Even if preservatives in cosmetics differ in their specific mechanism-of-action, they all have in common that there is not a specific microbial binding site [18]. Many antimicrobial agents rather bind promiscuously to microbial cell components as proteins or membranes. The interaction of non-covalent binders is rather short-term and multiple molecules can be involved. This is in strong contrast to most drugs, which intentionally attack a specific binding site of a single molecular target as enzymes or receptors. Fine-tuned shape and specific interaction lead to molecular recognition. Taken together, this indicates that the interaction between microbes and preservatives examined in this article is less driven by the presence of specific functional groups in a specific spatial constellation (as symbolized by pharmacophore model), but rather by more general molecular properties.

The objective of this study was to identify beneficial molecular characteristics of antimicrobial substances, which are successfully used in cosmetic products for preservations purposes. Therefore, we studied molecular characteristics of preservatives allowed in the EU. Our results highlight, that there are two distinctive privileged areas in chemical space, which can be defined by few simple parameters. These findings provide a guide for identification and optimization of new antimicrobial substances applicable for cosmetic preservation. 


\section{Materials and Methods}

The list of preservatives allowed in cosmetic products (Annex V, Regulation 1223/2009/ EC on Cosmetic Products [3], version of March 2018) was used as starting point for the analysis. When entries contain various salt forms, only one form was considered as no significant influence on activity is expected. Some entries contain derivatives of different alkyl chain lengths. In these cases, representative chain lengths (e.g., C12, C16, and C22 for Alkyl (C12-C22) trimethyl ammonium) were included in the analysis.

Substances were transformed into two relevant species: (1) the predominant species in cosmetic formulations at $\mathrm{pH}$ 6. Deprotonated species are used if $\mathrm{pKa}<6$. Dissociation of salts is expected, if no opposite information is available; (2) the active species interacting with microbials. Exemplary, organic acids as benzoic acid are thought to permeate as neutral species, even if they predominantly exist as anion at $\mathrm{pH}$ 6. Substances used for analysis as well as structure of predominant and active species can be found in Supporting Information Table S1.

Substances with a reactivity-based mechanism-of-action were excluded from closer empirical analysis. Information about the acceptance of underlying mechanisms are specified in the Supporting Information Table S1.

Various molecular properties were considered in the empirical analysis. Structural descriptors were derived from Lewis structure of an object. The formal net charge $(\mathrm{Q})$ and molecular weight (MW) were calculated using ChemDraw ${ }^{\circledR}$ Version 19.1.1.21 (PerkinElmer Informatics, Inc., Waltham, MA, USA). The number of rotatable bonds (nrotb) was calculated using Chem3D ${ }^{\circledR}$ Version 19.1.1.21 (PerkinElmer Informatics, Inc., Waltham, MA, USA). The number of hydrogen-bond donors (HBD) was determined by counting all $\mathrm{H}$-atoms bound to nitrogen or oxygen atoms in the Lewis structure. The number of hydrogen-bond acceptors (HBA) was determined by counting all nitrogen or oxygen atoms bearing lone electron pair in the Lewis structure to participate in hydrogen bonds. Hydrogen bonding capacity (HBDnA) was defined as sum of HBD and HBA. Descriptors of surface and shape as Connolly molecular surface area (MSA) and topological polar surface area (tPSA) were calculated using Chem $3 \mathrm{D}^{\circledR}$ Version 19.1.1.21 (PerkinElmer Informatics, Inc., Waltham, MA, USA). Before calculating MSA, structures were optimized using MM2 energy minimization using Minimum RMS Gradient of 0.010. MSA was calculated using a probe radius of 1.4. Physico-chemical parameters including distribution coefficient $(\log D)$ and aqueous solubility $(\log S)$ were calculated by ChemAxon $\log \mathrm{D}$ calculator [19] or Chem3D ${ }^{\circledR}$ Version 19.1.1.21 (PerkinElmer Informatics, Inc., Waltham, MA, USA), respectively. For logS calculation, the predominant species in water at $\mathrm{pH} 6$ was used to calculate solubility, as the carboxylate mainly contributes to solubility and availability in water phase and fast conversion to the active species is expected. For visualization, molecular characteristics were plotted using Microsoft $365^{\circledR}$ Excel $^{\circledR}$ (Microsoft Corporation).

\section{Results}

\subsection{Substance Set Description}

All entries listed as preservatives in Annex V of the Regulation (EC) No. 1223/2009 [3] were analyzed in this study (Supporting Information Table S1). Many substances are hardly accepted by consumers and several of these substances have a chemical reactivity-based mechanism-of-action. Thus, aldehydes and formaldehyde releaser, isothiazolinones, sulfur dioxide releasing sulfites, and substances based on heavy metals (such as mercury and silver) were excluded from analysis, since their mechanisms-of-action are irrelevant for future developments.

\subsection{Evaluation of Chemical Space Reveals Two Distinctive Areas}

Forty substances with accepted mechanism-of-action were analyzed regarding molecular properties (Table 1). A plot of total polar surface area (tPSA) versus Connolly molecular surface area (MSA) shows two distinctive groups (Figure 1). The first condensed group A (blue) is characterized by MSA between 49 and $263 \AA^{2}$ and tPSA between 20 and $92 \AA^{2}$. 
The second group B (red) is rather diffuse revealing MSA $\geq 320 \AA^{2}$ and no limitations for tPSA. No upper limit is given due to the polymer polyaminopropyl biguanide with a wide scattering of MSA and tPSA depending on varying chain length.

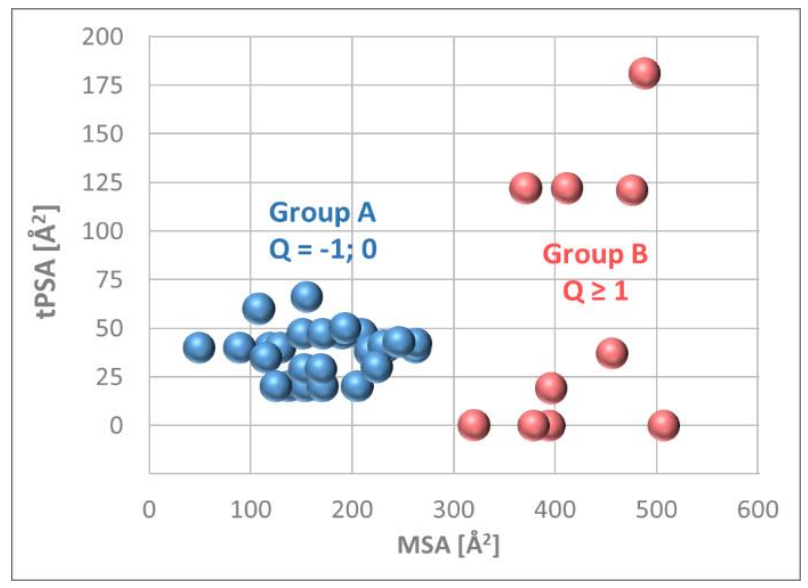

Figure 1. Two-dimensional plots of total polar surface area (tPSA) vs. Connolly molecular surface area (MSA): position of preservatives reveal two distinctive areas in chemical space for neutral or anionic (blue) and cationic (red) substances.

The distinctive property separating both groups is apparently the net charge $(Q)$, as members of group $B$ are cationic $(Q \geq 1)$. Members of group $A$ are either neutral or anionic in their predominant form at $\mathrm{pH}$ 6. As all anionics of group A have $\mathrm{pKa}$ values (of the conjugated acid) of at least 3.9, a significant percentage exist in their un-ionized form.

\subsection{Characterization of Molecular Chemical Space: Structural Descriptors}

\subsubsection{Molecular Size}

MSA is a measure of the size of a molecule. Alternatively, molecular weight (MW) can be used as indicator. Thereby, the distinction of both groups is less pronounced compared to MSA (Figure 2a). MW spans 45 to $316 \mathrm{~g} / \mathrm{mol}$ for group A, excluding bromochlorophene wearing two heavy bromine atoms, and $\mathrm{MW} \geq 257 \mathrm{~g} / \mathrm{mol}$ for cationics of group B. However, molecular weight is very easy to calculate and might be valuable as size indicator when searching for novel preservatives in both privileged areas.

\subsubsection{Flexibility}

The number of rotatable bond (nrotb) is a measure for a molecule's flexibility. Conformational adaption might facilitate target binding, however, restriction of rotatable bonds upon target binding leads to reduced affinity due to an entropic penalty [20]. Furthermore, flexibility allows conformations with different polar surface areas, having influence on aqueous solubility of a substance and solubilization of a substance-target adduct. Group A preservatives reveal nrotb $\leq 6$ with the exemption of undec-10-enoic acid, which shows higher flexibility (nrotb $=9$ ). In contrast, cationic substances of group B contain at least 11 rotatable bonds (Figure $2 b$ ). 


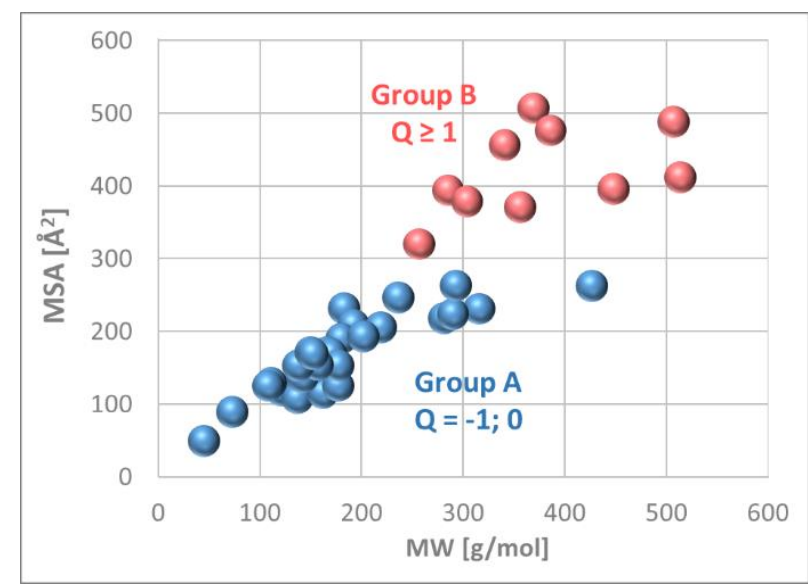

(a)

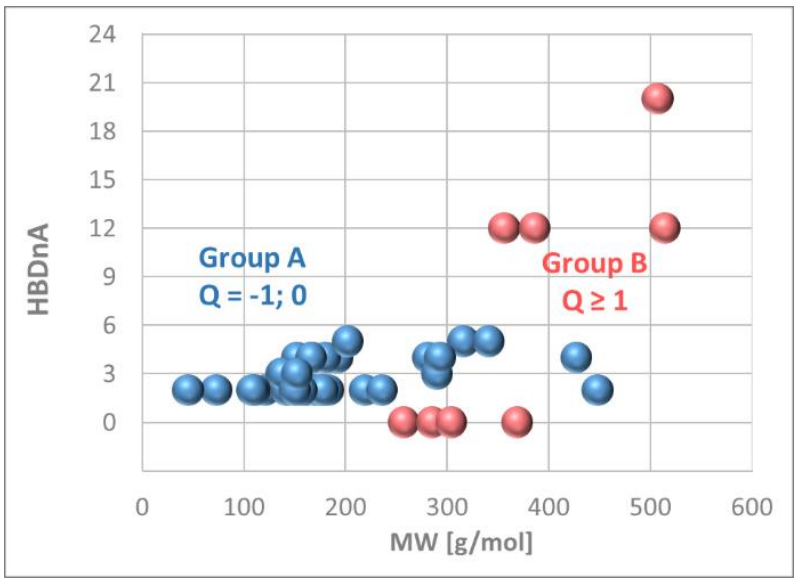

(c)

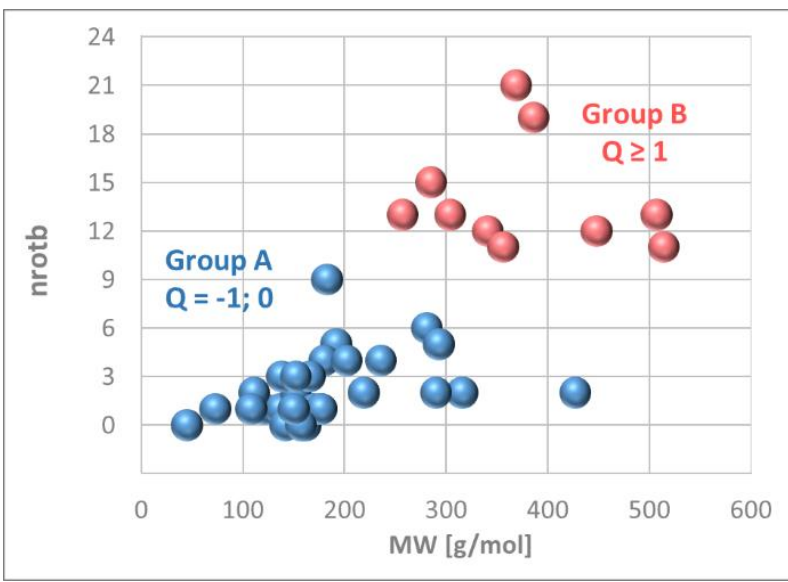

(b)

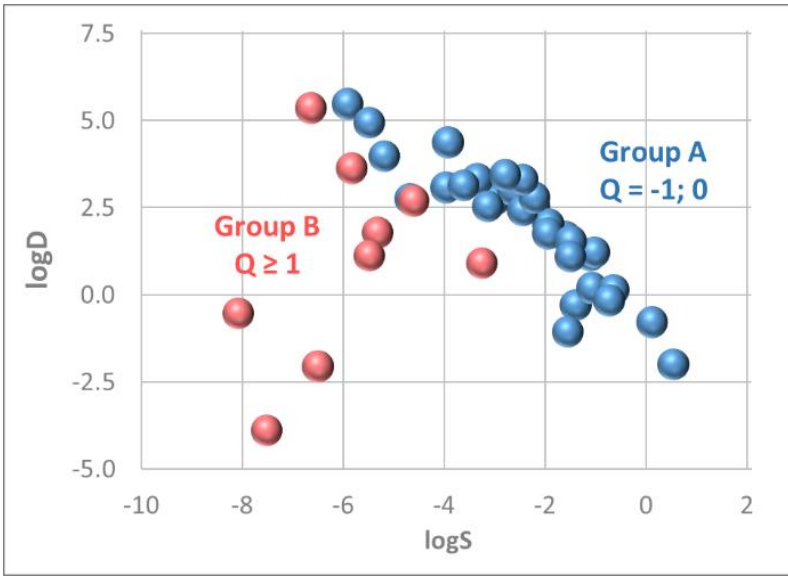

(d)

Figure 2. Two-dimensional plots including position of neutral or anionic (blue) and cationic (red) preservatives in chemical space: (a) plot of Connolly molecular surface area (MSA) vs. molecular weight (MW) as easily available alternative measure of size; (b) plot of number of rotatable bonds (nrotb) vs. MW; (c) plot of hydrogen bonding capacity (HBDnA) vs. MW; (d) plot of distribution coefficient $(\log D)$ vs. aqueous solubility $(\log S)$. 
Table 1. Calculated molecular descriptors of preservatives, which were used for empirical analysis of privileged chemical space.

\begin{tabular}{|c|c|c|c|c|c|c|c|c|c|c|c|c|c|}
\hline $\begin{array}{l}\text { Annex V } \\
\text { Ref. No. }\end{array}$ & Preservative $^{1}$ & $\mathrm{Q}^{2,3}$ & $\underset{\left(\AA^{2}\right)}{\operatorname{MSA}}$ & $\begin{array}{l}\text { tPSA }^{1} \\
\left(\AA^{2}\right)\end{array}$ & $\begin{array}{c}\mathrm{MW}^{1} \\
(\mathrm{~g} / \mathrm{mol})\end{array}$ & nrotb $^{1}$ & $\mathrm{HBD}^{1}$ & HBA $^{1}$ & HBDnA $^{1}$ & $\log D$ & $\log S^{1}$ & $\mathrm{MoA}^{3}$ & Group \\
\hline 1 & Benzoic acid and its salts & $-1(0)$ & 119 & 40 & 121 & 1 & 0 & 2 & 2 & -0.29 & -1.39 & \multirow{7}{*}{$\begin{array}{l}\text { Protonophores; } \\
\text { causing membrane } \\
\text { depolariz. [21] }\end{array}$} & \multirow{7}{*}{ A } \\
\hline 2 & Propionic acid and its salts & $-1(0)$ & 89 & 40 & 73 & 1 & 0 & 2 & 2 & -0.79 & 0.12 & & \\
\hline 3 & Salicylic acid and its salts & $-1(0)$ & 108 & 60 & 137 & 1 & 1 & 3 & 3 & -1.06 & -1.55 & & \\
\hline 4 & Sorbic acid and its salts & $-1(0)$ & 129 & 40 & 111 & 2 & 0 & 2 & 2 & 0.20 & -1.07 & & \\
\hline 8 & Pyrithione zinc (here: pyrithione) & $-1(0)$ & 115 & 35 & 162 & 0 & 0 & 2 & 2 & 0.14 & -0.64 & & \\
\hline 13 & Dehydroacetic acid and its salts & $-1(0)$ & 155 & 66 & 167 & 1 & 0 & 4 & 4 & -0.16 & -0.73 & & \\
\hline 14 & Formic acid and its salts & $-1(0)$ & 49 & 40 & 45 & 0 & 0 & 2 & 2 & -2.00 & 0.54 & & \\
\hline 18 & Undec-10-enoic acid and its salts & $-1^{4}$ & 232 & 40 & 183 & 9 & 0 & 2 & 2 & 2.71 & -3.01 & -4 & $\mathrm{~A}$ \\
\hline 12 bis & Butyl 4-hydroxybenzoate & 0 & 209 & 47 & 192 & 5 & 1 & 3 & 4 & 3.00 & -2.64 & \multirow{4}{*}{$\begin{array}{l}\text { Mechanism } \\
\text { is unclear }{ }^{5}\end{array}$} & \multirow{4}{*}{$\mathrm{A}$} \\
\hline $12 \mathrm{bis}$ & Propyl 4-hydroxybenzoate & 0 & 190 & 47 & 180 & 4 & 1 & 3 & 4 & 2.55 & -2.22 & & \\
\hline 12 & Methylparaben & 0 & 151 & 47 & 152 & 2 & 1 & 3 & 4 & 1.67 & -1.60 & & \\
\hline 12 & Ethylparaben & 0 & 171 & 47 & 166 & 3 & 1 & 3 & 4 & 2.03 & -1.94 & & \\
\hline 7 & Biphenyl-2-ol & 0 & 169 & 20 & 170 & 1 & 1 & 1 & 2 & 3.32 & -3.34 & \multirow{10}{*}{$\begin{array}{l}\text { Solubilization of lipids } \\
\text { and denaturing proteins } \\
\text { [21] }\end{array}$} & \multirow{10}{*}{$\mathrm{A}$} \\
\hline 11 & Chlorobutanol & 0 & 125 & 20 & 177 & 1 & 1 & 1 & 2 & 1.75 & -1.95 & & \\
\hline 22 & 2,4-Dichlorobenzyl alcohol & 0 & 153 & 20 & 177 & 1 & 1 & 1 & 2 & 2.41 & -2.44 & & \\
\hline 24 & Chlorocresol & 0 & 137 & 20 & 142 & 0 & 1 & 1 & 2 & 2.79 & -2.21 & & \\
\hline 26 & Chloroxylenol & 0 & 154 & 20 & 157 & 0 & 1 & 1 & 2 & 3.30 & -2.44 & & \\
\hline 29 & 2-Phenoxyethanol & 0 & 153 & 29 & 138 & 3 & 1 & 2 & 3 & 1.13 & $\begin{array}{l}-2.44 \\
-1.10\end{array}$ & & \\
\hline 38 & 4-Isopropyl-m-cresol & 0 & 171 & 20 & 150 & 1 & 1 & 1 & 2 & 3.43 & -2.79 & & \\
\hline 40 & Chlorophene & 0 & 205 & 20 & 219 & 2 & 1 & 1 & 2 & 4.37 & -3.92 & & \\
\hline 43 & 1-Phenoxypropan-2-ol & 0 & 169 & 29 & 152 & 3 & 1 & 2 & 3 & 1.54 & -1.49 & & \\
\hline 50 & Chlorphenesin & 0 & 193 & 50 & 202 & 4 & 2 & 3 & 5 & 1.10 & -1.50 & & \\
\hline 56 & $\begin{array}{c}\text { 3-Iodo-2- } \\
\text { propynylbutylcarbamate }\end{array}$ & 0 & 218 & 38 & 281 & 6 & 1 & 3 & 4 & 2.54 & -3.14 & - & $\mathrm{A}$ \\
\hline 23 & Triclocarban & 0 & 231 & 41 & 316 & 2 & 2 & 3 & 5 & 4.93 & -5.48 & \multirow{5}{*}{$\begin{array}{l}\text { Intracell. enzyme } \\
\text { inhibitors [22-25] }\end{array}$} & \multirow{4}{*}{ A } \\
\hline 25 & Triclosan & 0 & 224 & 30 & 290 & 2 & 1 & 2 & 3 & 4.97 & -5.19 & & \\
\hline 32 & Climbazol & 0 & 263 & 42 & 293 & 5 & 0 & 4 & 4 & 3.07 & -3.96 & & \\
\hline 35 & $\begin{array}{l}\text { Piroctone and its } \\
\text { monoethanolamine salt }\end{array}$ & -1 & 246 & 43 & 236 & 4 & 0 & 2 & 2 & 3.13 & -3.62 & & \\
\hline 19 & Hexetidine & 1 & 456 & 37 & 341 & 12 & 3 & 2 & 5 & 2.75 & -4.67 & & B \\
\hline
\end{tabular}


Table 1. Cont.

\begin{tabular}{|c|c|c|c|c|c|c|c|c|c|c|c|c|c|}
\hline $\begin{array}{l}\text { Annex V } \\
\text { Ref. No. }\end{array}$ & Preservative $^{1}$ & $\mathbf{Q}^{2,3}$ & $\begin{array}{l}\operatorname{MSA}^{1} \\
\left(\AA^{2}\right)\end{array}$ & $\begin{array}{l}\text { tPSA }^{1} \\
\left(\AA^{2}\right)\end{array}$ & $\begin{array}{c}\mathrm{MW}^{1} \\
(\mathrm{~g} / \mathrm{mol})\end{array}$ & nrotb $^{1}$ & HBD $^{1}$ & HBA $^{1}$ & HBDnA $^{1}$ & $\log \mathrm{D}$ & $\log S^{1}$ & $\mathrm{MoA}^{3}$ & Group \\
\hline 15 & Dibromohexamidine and its salts & 2 & 412 & 122 & 514 & 11 & 8 & 4 & 12 & -0.53 & -8.08 & \multirow{10}{*}{$\begin{array}{l}\text { Interaction with } \\
\text { membrane component } \\
\text { destroying membrane } \\
\text { integrity [21] }\end{array}$} & \multirow{10}{*}{ B } \\
\hline 28 & $\begin{array}{l}\text { Polyaminopropyl biguanide } \\
\text { (here: } n=22 \text { ) }\end{array}$ & 22 & 4932 & 1881 & 4000 & 176 & 132 & 88 & 220 & - & -2.82 & & \\
\hline 42 & Chlorhexidin and its salts & 2 & 488 & 181 & 507 & 13 & 12 & 8 & 20 & -3.90 & -7.52 & & \\
\hline 44 & $\begin{array}{c}\text { Alkyl (C12-C22) trimethyl } \\
\text { ammonium salts }{ }^{6} \text { (here: C12) }\end{array}$ & 1 & 320 & 0 & 257 & 13 & 0 & 0 & 0 & 0.91 & -3.25 & & \\
\hline 44 & $\begin{array}{l}\text { Alkyl (C12-C22) trimethyl } \\
\text { ammonium salts }{ }^{6} \text { (here: C16) }\end{array}$ & 1 & 394 & 0 & 285 & 15 & 0 & 0 & 0 & 2.69 & -4.61 & & \\
\hline 44 & $\begin{array}{l}\text { Alkyl (C12-C22) trimethyl } \\
\text { ammonium salts }{ }^{6} \text { (here: C22) }\end{array}$ & 1 & 507 & 0 & 369 & 21 & 0 & 0 & 0 & 5.35 & -6.64 & & \\
\hline 47 & Hexamidine and its salts & 2 & 371 & 122 & 356 & 11 & 8 & 4 & 12 & -2.06 & -6.50 & & \\
\hline 53 & Benzethonium chloride & 1 & 396 & 19 & 448 & 12 & 0 & 2 & 2 & 1.78 & -5.32 & & \\
\hline 54 & Benzalkonium salts ${ }^{7}$ (here: $\mathrm{C} 12$ ) & 1 & 379 & 0 & 304 & 13 & 0 & 0 & 0 & 3.63 & -5.83 & & \\
\hline 58 & $\begin{array}{c}\text { Ethyl Lauroyl Arginate } \\
\text { Hydrochloride }\end{array}$ & 1 & 476 & 121 & 386 & 19 & 6 & 6 & 12 & 1.12 & -5.48 & & \\
\hline
\end{tabular}

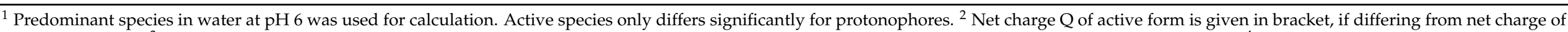

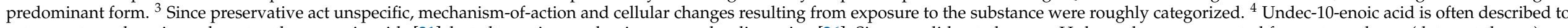

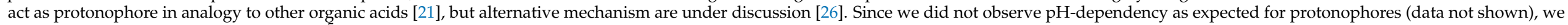

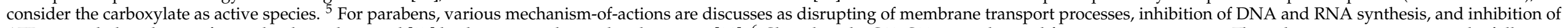

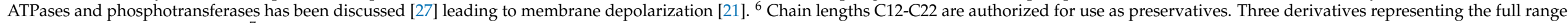

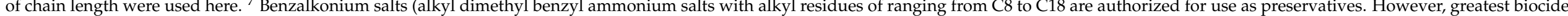
activity is associated with C12-C14 derivatives, which are the main components [28] 


\subsubsection{Hydrogen Bonding}

Hydrogen bonding strongly contributes to the interaction capacity of a substance with a biomolecular target and surrounding solvent. This has impact on affinity to microbial targets, but also on solubility and distribution within a cosmetic formulation. Therefore, we analyzed the overall hydrogen-bonding capacity (HBDnA) as calculated by the sum of hydrogen-bond donors (HBD) and hydrogen-bond acceptors (HBA) (Figure 2c). Group A revealed HBDnA between 2 and 6. Cationic group B did not show limitations as HBDnA can be very high for the polymer polyaminopropyl biguanide, whereas quaternary ammonium compounds cannot form hydrogen bonds. Individual numbers of HBD or HBA revealed same pattern of distribution (Supporting Information Figure S2), and thus, do not provide additional value.

\subsection{Physicochemical Properties: Lipophilicity and Solubility}

\subsubsection{Lipophilicity}

Lipophilicity is a crucial property as it represents the affinity of a molecule for a lipophilic environment. Keeping in mind that cosmetic formulations usually consist of multiple phases, a substance's lipophilicity has direct impact on the distribution and availability at the target site. Furthermore, lipophilicity affects the affinity of a molecule for microbial binding sites.

Many preservatives analyzed in this study are ionizable. Since neutral and ionic forms exhibit different polarities, a substance's lipophilicity depends on $\mathrm{pH}$. Thus, we calculated the distribution coefficient $\log \mathrm{D}$ for evaluation of lipophilicity, as it considers all species of a molecule at a given $\mathrm{pH}$, which was representatively set to $\mathrm{pH} 6$ in this study. Both groups $A$ and $B$ revealed similar distribution of $\log D$ values in the range between -4 and 5.5 (Figure 2d).

\subsubsection{Solubility}

Aqueous solubility is an upper limit for the concentration of a substance in aqueous phase. Since antimicrobials are expected to be located in aqueous phase to be efficient [17], solubility is crucial for antimicrobial activity. Calculated $\log S$ values lie between -6 and 0.5 for group A, and between -2.8 and 8.1 for cationic substances of group B (Figure 2d). However, some cationics have amphiphilic properties and might form aggregates in bulk water. Furthermore, it is important to note that calculated solubility might be inaccurate in some cases compared to experimental values. Nevertheless, the calculated logS range of preservatives can be used in the search for novel preservatives when compared to calculated $\log S$ of candidates.

\section{Discussion}

\subsection{Calculation and Analysis of Molecular Desciptors}

In analogy to the concept of drug-likeness, we expected that there is a privileged chemical space for cosmetic preservatives. Therefore, various molecular descriptors and properties were analyzed.

Preservatives in cosmetic products might exist in various forms as different protonation states or even might undergo chemical reactions. Many of the molecular descriptors examined depend on the molecular species used for calculation. There are two forms pivotal for antimicrobial activity in cosmetics: (1) the predominant species in cosmetic formulations, which determines the substance's location within a cosmetic formulation, and thus, availability at the target site; (2) the active species interacting with microbes, which is the crucial form for antimicrobial activity. The original form as added to the cosmetic formulation is considered as irrelevant as fast conversion to the predominant species is expected.

Conspicuously, for all substances with accepted mechanism-of-action, the predominant and active species differed in protonation state only. As there are only minor differences in molecular descriptors, we have focused on the predominant form if not stated 
otherwise. For calculation of aqueous solubility, which might be considered as an upper limit for the concentration in the aqueous phase, use of the predominant species is reasonable as this species is, per definition, the thermodynamically favored one contributing most to the overall solubility.

To measure lipophilicity of drug candidates, Lipinski and others used the partition coefficient $\log \mathrm{P}$, which refers to the partitioning of un-ionized compound between octan-1ol and water. For drugs this appears reasonable due to the hypothesis, that absorption of ionizable drugs takes place where the local $\mathrm{pH}$ provides the maximum concentration of non-ionized form [29]. However, the effectiveness of preservatives in cosmetics depends on distribution into the aqueous phase [17]. As fast conversion between ionized and un-ionized form is expected, all species are relevant. Thus, the distribution coefficient $\log \mathrm{D}$, which considers all forms of a compounds (ionized plus un-ionized) at the given $\mathrm{pH}$ (here: $\mathrm{pH}$ 6) was used as descriptor for lipophilicity in this study. One might argue that for interaction with the microbial target, only the lipophilicity of the active form of an antimicrobial is relevant. This applies to organic acids only, as they penetrate as neutral molecules into microbials cells even if the predominant species is ionized. Indeed, clogP values of organic acids were increased compared to ionized carboxylates but remain in a typical range for group A members.

\subsection{Dependencies of Molecular Descriptors}

Among various molecular properties analyzed in this study, close correlations were found. As stated above, molecular weight and molecular surface area are both measures of size, and thus, intrinsically correlate to some degree. To keep the rules easily applicable for future searches, definition of privileged chemical space should be limited to independent properties providing additional value. From this perspective, consideration of size can be limited to molecular weight, which is easily accessible.

In a modification of Lipinski's rules, number of rotatable bonds rather than molecular weight was proposed as crucial measure for oral drug bioavailability [15]. As the chance for high number of rotatable bonds increases with number of bonds, some degree of dependency between nrotb and MW can be expected. However, we found a wide distribution for nrotb/MW, demonstrating independence of flexibility and size (Supporting Information Figure S2). In analogy to nrotb, we found low nrotb/MW for neutral and anionic molecules, and significantly higher nrotb/MW for cationics, legitimating the use of nrotb to define the areas of preservatives in chemical space.

A correlation between total polar surface area and interaction capacity, more precisely the sum of hydrogen-bonding donors and acceptors, was identified. tPSA as typically calculated arises from oxygen and nitrogen atoms including hydrogen attached to oxygen and nitrogen [30], which are the moieties contributing to hydrogen bonding. Thus, there is a causal association and consideration can be limited to tPSA, as hydrogen-bonding alone does not give additional value [20]. Taking into account further interactions, e.g., ionic or van der Waals forces, leading to a hypothetic overall interaction capacity is expected to reduce dependency on tPSA.

\subsection{Mechanism-of-Action and Rules for Privileged Chemical Space}

We suppose that a set of compounds sharing the same mechanism-of-action also share beneficial molecular characteristics. However, in contrast to antibiotics acting on specific sites of biosynthetic processes, preservatives have multiple targets [10]. At microbicidal concentrations, direct and indirect cellular effects can hardly be distinguished. Thus, we categorized all preservatives in rough classes (Table 1) and analyzed their position in chemical space.

As stated above, the cationic group interacting with membrane components occupy a distinctive area in chemical space. Hexetidine, which almost entirely exist in cationic form (pKa 8.3), shares key characteristics of this group as charge, high molecular size, and high 
flexibility, and thus, strongly differs from the members of intracellular inhibitor groups (see Supporting Information Figure S3).

All mechanism-of-action categories bearing neutral and anionic substances are in a common area of chemical space. There are only trends as protonophores tend to be small and share $\operatorname{low} \log \mathrm{D}$ and high $\log \mathrm{S}$ values due to predominant existence as carboxylate. Small size and pKa values, which allow a minor part to exist as neutral molecules, enable penetration into microbial cells. However, there is no clear distinction but rather strong overlap with other categories.

Interestingly, undec-10-enoic acid reveals significant higher flexibility compared to other group members (nrotb $=9$ vs. $\leq 6$ ). Furthermore, unlike for protonophores we did not observe tremendous activity drop when $\mathrm{pH}$ is increased above 6, which indicates that the ionized carboxylate is the active species (data not shown). Both observations might support alternative mechanism-of-actions as cytoplasmic membrane disruption [26]. In any case, anionic substances bearing a high flexibility might represent an under-exploited category.

Taking our findings together, we postulate a privileged area for neutral or anionic cosmetic preservation narrowed down to $\mathrm{MW}=40-320 \mathrm{~g} / \mathrm{mol}$, nrotb $\leq 6, \mathrm{tPSA}=20-100 \AA^{2}$, $\log \mathrm{D}=-4-6, \log S=-6-6$. For cationics, privileged area is characterized by $\mathrm{MW} \geq 250 \mathrm{~g} / \mathrm{mol}$, nrotb $\geq 11$, no limitations for tPSA, $\log \mathrm{D}=-4-6, \log S=-3-9$. This does not mean that substances fulfilling these criteria are necessarily strong antimicrobials; however, substances in privileged chemical space have been shown to comply with requirements of cosmetic preservatives, which includes availability at target site. Thus, the criteria can serve as guide for future developments.

\subsection{Comparison of Cosmetic Preservatives with Marketed Drugs and Antibiotics}

Lipinski's work marked the starting point for the analysis of physicochemical properties of various substance sets including marketed antibiotics [5,31,32]. Keeping the fundamental differences of application between antibiotics and cosmetic preservatives in mind, we compared molecular properties of both substance sets (Table 2).

Table 2. Average values of molecular characteristics. Comparison between cosmetic preservatives and antimicrobial drugs.

\begin{tabular}{|c|c|c|c|c|c|}
\hline $\begin{array}{l}\text { Molecular } \\
\text { Property }\end{array}$ & $\begin{array}{l}\text { Annex } V^{1} \\
(Q=-1 ; 0)\end{array}$ & $\begin{array}{l}\text { Annex } V^{1,2} \\
(Q \geq 1)\end{array}$ & $\begin{array}{c}\text { Antibiotics }^{3} \\
\text { (Gram-Positive) }\end{array}$ & $\begin{array}{c}\text { Antibiotics }^{3} \\
\text { (Gram-Negative) }\end{array}$ & Non-Antibiotics ${ }^{3}$ \\
\hline MW & 184 & 377 & 813 & 414 & 338 \\
\hline nrotb & 2.3 & 14.0 & 13.8 & 6.8 & 5.9 \\
\hline tPSA & 36 & 60 & 243 & 165 & 70 \\
\hline HBDnA & 2.9 & 6.3 & 23.4 & 14.5 & 6.5 \\
\hline $\log \mathrm{D}$ & 1.98 & 1.17 & -0.20 & -2.79 & 1.59 \\
\hline $\log S$ & -2.33 & -5.79 & - & - & - \\
\hline
\end{tabular}

${ }^{1}$ Cosmetic preservatives with accepted mechanism-of-action as analyzed in this study and listed in Table $1 .{ }^{2}$ For calculation of average values, the polymer polyaminopropyl biguanide was not considered. ${ }^{3}$ Average values as calculated by $\mathrm{O}^{\prime}$ Shea et al. [31]. Minor differences between the calculation process might result in slightly different numbers.

Obviously, compared to antibiotic substance sets, neutral or anionic cosmetic preservatives are simple molecules characterized by small size and low hydrogen-bonding capabilities. Antibiotics, in particular if active against Gram-positive bacteria, have higher molecular weight, and higher numbers of hydrogen-bond donors and acceptors. An overall increased polarity is also reflected by increased tPSA and decreased $\log \mathrm{D}$.

Cationic preservatives have similar size as antibiotics for Gram-negative bacteria. However, they are characterized by higher proportion of rotatable bonds, and lower polarity as revealed by total polar surface area, hydrogen-bonding capacity, and distribution coefficient $\log \mathrm{D}$.

Thus, cosmetic preservatives occupy a completely different area in chemical space than antibiotics do. This might reflect the differences in mechanism-of-action of antibiotics and preservatives, as the latter do not need multiple interactions for specific target 
recognition. Molecular properties of the preservative's privileged chemical spaces rather combine two crucial requirements, availability at the site of action and favorable interactions with microbes. This can guide future efforts to identify new ingredients for cosmetic preservation.

Supplementary Materials: The following are available online at https:/ /www.mdpi.com/article/ 10.3390/ cosmetics8030080/s1, Table S1: List of substances including acceptance of mechanism-ofaction and structures; Figure S2: Additional plots; Figure S3: Plots of MoA categories.

Author Contributions: Conceptualization, M.P.S.; Methodology, M.P.S.; Writing-original draft preparation, M.P.S.; Writing-review and editing, M.P.S. and L.H.; Visualization, M.P.S.; Project administration, M.P.S. and L.H.; Funding Acquisition, M.P.S. and L.H. All authors have read and agreed to the published version of the manuscript.

Funding: This research was funded by the European Union—Regional Development Fund, grant number 09518 001, project number LPW-E/1.2.3/895.

Institutional Review Board Statement: Not applicable.

Informed Consent Statement: Not applicable.

Data Availability Statement: Data is contained within the article.

Conflicts of Interest: The authors declare no conflict of interest. The funders had no role in the design of the study; in the collection, analyses, or interpretation of data; in the writing of the manuscript, or in the decision to publish the results.

\section{References}

1. Becks, V.E.; Lorenzoni, N.M. Pseudomonas aeruginosa Outbreak in a Neonatal Intensive Care Unit: A Possible Link to Contaminated Hand Lotion. Am. J. Infect. Control 1995, 23, 396-398. [CrossRef]

2. Safety Gate: The EU Rapid Alert System for Dangerous Non-Food Products. Available online: https:/ /ec.europa.eu/safety-gatealerts/screen/webReportusingsearchforalertoption (accessed on 22 April 2021).

3. The European Parliament and the Council of the European Union. Regulation (EC) No. 1223/2009 of the European Parliament and of the Council of 30 November 2009 on Cosmetic Products-Consolidated Version of 25/12/2017. Off. J. Eur. Union Lex 2009, 342,59 .

4. McLaughlin, J.K. Formaldehyde and cancer: A critical review. Int. Arch. Occup. Environ. Heath 1994, 66, 295-301. [CrossRef]

5. De Groot, A.C.; Flyvholm, M.-A.; Lensen, G.; Menné, T.; Coenraads, P.-J. Formaldehyde-releasers: Relationship to formal-dehyde contact allergy. Contact allergy to formaldehyde and inventory of formaldehyde-releasers. Contact Dermat. 2009, 61, 63-85. [CrossRef]

6. Denyer, S.P. Mechanisms of Action of Antibacterial Biocides. Int. Biodeterior. 1995, 36, 221-245. [CrossRef]

7. Swenberg, J.A.; Moeller, B.C.; Lu, K.; Rager, J.E.; Fry, R.C.; Starr, T.B. Formaldehyde Carcinogenicity Research: 30 Years and Counting for Mode of Action, Epidemiology, and Cancer Risk Assessment. Toxicol. Pathol. 2013, 41, 181-189. [CrossRef] [PubMed]

8. Williams, T.M. The Mechanism of Action of Isothiazolone Biocides. Power Plant Chem. 2007, 9, 14-22.

9. Irwin, S.V.; Fisher, P.; Graham, E.; Malek, A.; Robidoux, A. Sulfites Inhibit the Growth of Four Species of Beneficial Gut Bacteria at Concentrations Regarded as Safe for Food. PLoS ONE 2017, 12, e0186629. [CrossRef]

10. Halla, N.; Fernandes, I.P.; Heleno, S.A.; Costa, P.; Boucherit-Otmani, Z.; Boucherit, K.; Rodrigues, A.E.; Ferreira, I.C.F.R.; Barreiro, M.F. Cosmetics Preservation: A Review on Present Strategies. Molecules 2018, 23, 1571. [CrossRef]

11. Shepherd, J.A.; Waigh, R.D.; Gilbert, P. Antibacterial Action of 2-Bromo-2-Nitropropane-1,3-Diol (Bronopol). Antimicrob. Agents Chemother. 1988, 32, 1693-1698. [CrossRef]

12. Ghannoum, M.; Thomson, M.; Bowman, W.; Al-Khalil, S. Mode of Action of the Antimicrobial Compound 5-Bromo-5-nitro-1,3dioxane (Bronidox). Folia Microbiol. 1986, 31, 19-31. [CrossRef] [PubMed]

13. Yin, E.X.; Zhang, J.; Zhao, E.S.; Mei, M.L.; Li, Q.; Chu, C.H. The Antibacterial Mechanism of Silver Nanoparticles and Its Application in Dentistry. Int. J. Nanomed. 2020, 15, 2555-2562. [CrossRef]

14. Lipinski, C.A.; Lombardo, F.; Dominy, B.W.; Feeney, P.J. Experimental and Computational Approaches to Estimate Solubility and Permeability in Drug Discovery and Development Settings. Adv. Drug Deliv. Rev. 1997, 23, 3-25. [CrossRef]

15. Veber, D.F.; Johnson, S.R.; Cheng, H.-Y.; Smith, B.R.; Ward, K.W.; Kopple, K.D. Molecular Properties That Influence the Oral Bioavailability of Drug Candidates. J. Med. Chem. 2002, 45, 2615-2623. [CrossRef] [PubMed]

16. Maillard, J.-Y. Factors Affecting the Activities of Microbicides. In Hugo and Ayliffe's Principles and Practice of Disinfection, Preservation and Sterilization, 5th ed.; Fraise, A.P., Maillard, J.-Y., Sattar, S.A., Eds.; John Wiley \& Sons: Hoboken, NJ, USA, 2013; pp. 71-86.

17. Tschierske, N.; Emeis, D.; Biel, S.S. Efficacy Loss of Antimicrobial Actives in Emulsions. SOFW-J. 2012, 4, 1-4.

18. Denyer, S.P. Mechanism of Action of Biocides. Int. Biodeterior. 1990, 26, 89-100. [CrossRef] 
19. Available online: https://disco.chemaxon.com/calculators/demo/plugins/logd/ (accessed on 15 April 2021).

20. Bradley, C.D.; Kihlberg, J. Drug Discovery Beyond the Rule of 5-Opportunities and Challenges. Expert Opin. Drug Discov. 2017, 12, 115-119. [CrossRef]

21. Geis, P.A. Appendix: Common Cosmetic Preservatives. In Cosmetic Microbiology A Practical Guide, 2nd ed.; Geis, P.A., Ed.; Taylor \& Francis Group: New York, NY, USA, 2006; pp. 228-281.

22. Macsics, R.; Hackl, M.W.; Fetzer, C.; Mostert, D.; Bender, J.; Layer, F.; Sieber, S.A. Comparative Target Analysis of Chlorinated Biphenyl Antimicrobials Highlights MenG as a Molecular Target of Triclocarban. Appl. Environ. Microbiol. 2020, 86, e00933-20. [CrossRef]

23. Russell, D. Whither triclosan? J. Antimicrob. Chemother. 2004, 53, 693-695. [CrossRef]

24. Richter, E.; Wick, A.; Ternes, T.A.; Coors, A. Ecotoxicity of Climbazole, a Fungicide Contained in Antidandruff Shampoo. Environ. Toxicol. Chem. 2013, 32, 2816-2825. [CrossRef]

25. do Couto, F.M.; do Nascimento, S.C.; Júnior, S.F.; da Silva, V.K.; Leal, A.F.; Neves, R.P. Antifungal Activity of the Piroctone Olamine in Experimental Intra-Abdominal Candidiasis. SpringerPlus 2016, 5, 468. [CrossRef]

26. Casillas-Vargas, G.; Ocasio-Malavé, C.; Medina, S.; Morales-Guzmán, C.; Del Valle, R.G.; Carballeira, N.M.; Sanabria-Ríos, D.J. Antibacterial Fatty Acids: An update of Possible Mechanisms of Action and Implications in the Development of the Next-generation of Antibacterial Agents. Prog. Lipid Res. 2021, 82, 101093. [CrossRef]

27. Valkova, N.; Lépine, F.; Valeanu, L.; Dupont, M.; Labrie, L.; Bisaillon, J.G.; Beaudet, R.; Shareck, F.; Villemur, R. Hydrolysis of 4-Hydroxybenzoic Acid Esters (Parabens) and Their Aerobic Transformation into Phenol by the Resistant Enterobacter cloacae Strain EM. Appl. Environ. Microbiol. 2001, 67, 2404-2409. [CrossRef] [PubMed]

28. Pereira, B.M.P.; Tagkopoulos, I. Benzalkonium Chlorides: Uses, Regulatory Status, and Microbial Resistance. Appl. Environ. Microbiol. 2019, 85, e00377-19.

29. Constantinescu, T.; Lungu, C.N.; Lung, I. Lipophilicity as a Central Component of Drug-Like Properties of Chalchones and Flavonoid Derivatives. Molecules 2019, 24, 1505. [CrossRef] [PubMed]

30. Caron, G.; Ermondi, G. Molecular Descriptors for Polarity: The Need for Going Beyond Polar Surface Area. Future Med. Chem. 2016, 8, 2013-2016. [CrossRef] [PubMed]

31. O'Shea, R.; Moser, H.E. Physicochemical Properties of Antibacterial Compounds: Implications for Drug Discovery. J. Med. Chem. 2008, 51, 2871-2878. [CrossRef] [PubMed]

32. Ebejer, J.-P.; Charlton, M.H.; Finn, P.W. Are the Physicochemical Properties of Antibacterial Compounds Really Different From Other Drugs? J. Cheminform. 2016, 8, 30. [CrossRef] 